\title{
Foix-Chavany-Marie syndrome in a 17-year-old female with congenital cytomegalovirus infection
}

\author{
This article was published in the following Dove Press journal: \\ Neuropsychiatric Disease and Treatment \\ 20 November 2014 \\ Number of times this article has been viewed
}

\author{
Renata Conforti' \\ Raffaella Capasso' \\ Guglielmo Capaldo² \\ Clemente Dato ${ }^{2}$ \\ Dario Saracino ${ }^{2}$ \\ Giuseppe Di lorio² \\ Mariarosa A Melone ${ }^{2}$ \\ 'Neuroradiology Unit, ${ }^{2}$ Division \\ of Neurology and Interuniversity \\ Centre for Research in Neuroscience, \\ Department of Clinical and \\ Experimental Medicine and Surgery, \\ Second University of Naples, \\ Naples, Italy
}

\begin{abstract}
Foix-Chavany-Marie syndrome is characterized by bilateral facio-glosso-pharyngomasticatory paralysis of voluntary movement due to bilateral anterior opercular lesions. We describe the case of a 17-year-old female affected by Foix-Chavany-Marie syndrome and congenital cytomegalovirus infection, evaluating the possible etiopathogenetic correlation between cerebral cortical dysplasia and intrauterine infections.
\end{abstract}

Keywords: Foix-Chavany-Marie syndrome, opercular syndrome, cytomegalovirus, cortical dysplasia, polymicrogyria

\section{Introduction}

Foix-Chavany-Marie syndrome (FCMS), also known as opercular syndrome, is characterized by bilateral paralysis of the facio-glosso-pharyngo-masticatory muscles in voluntary movement due to bilateral anterior opercular lesions, with normal strength in involuntary actions (such as yawning or laughing). ${ }^{1,2}$ Functional or structural interruption of the connections between the cortical motor areas and the brainstem nuclei is responsible for the symptoms of FCMS. The symptoms arise from damage to the bilateral projections connecting the anterior insular opercula and the nuclei of cranial nerves V, VII, IX, X and XII. ${ }^{3}$ In children, FCMS is a rare occurrence, and three main clinical forms have been described: ${ }^{3}$ developmental or evolutionary (secondary to cortical Sylvian dysplasia and pachypolymicrogyria in children caused by prenatal vascular lesions and/or infections of the central nervous system); ${ }^{4}$ acute-subacute (usually secondary to herpes simplex or tubercular infection) ${ }^{3}$ and transitory, in children affected by Rolandic epilepsy (this form, benign and reversible, usually occurs during status epilepticus). ${ }^{1,5}$

\section{Case report}

A 17-year-old Caucasian female came under our observation with a history of full-term precipitous delivery. At birth, the Apgar score was 7 at minute 1 and 9 at minute 5, and she showed postnatal hepatosplenomegaly, jaundice, and a petechial rash on her face, limbs, and trunk. Motor development was delayed: she gained head control at 4 months, the ability to sit at 12 months, the ability to stand unassisted at 13 months, and learned to walk, albeit precariously, at 20 months. By this time, no verbal language had developed nor had she gained adequate voluntary control over chewing and tongue movements. When she was one year old, clinical examination showed bilateral sensorineural hearing loss and mild mental retardation. An auditory prosthesis was implanted, and logopedistic rehabilitation was suggested. Transfontanellar ultrasonography, made possible by persistent opening of the fontanelle over 12 months, showed mild dilatation of the ventricular system, more prominent in the left lateral ventricle
Correspondence: Mariarosa A Melone Division of Neurology, Department of Clinical and Experimental Medicine and Surgery, School of Medicine, Second University of Naples, Is 8 Ed 105 Via Sergio Pansini, Naples 8013 I, Italy $\mathrm{Tel}+3908 \quad 15666810$

Fax +390815666805

Email marina.melone@unina2.it 
than in the right, in association with bilateral parenchymal calcifications. A diagnosis of congenital cytomegalovirus (CMV) infection with intracranial calcifications was made. Clinical examination at admission to our institution when she was 17 years old showed myopathic facies with amimia, bilateral hyposthenia of the facial muscles, an elongated and partially protruded tongue, an ogival palate, and bilateral claw hands.

Neurologic examination showed a lack of speech with emission of inarticulate sounds and severe deafness. She was able to understand spoken language and communicate using international sign language. There was salivary incontinence due to facial muscle hyposthenia, tongue protrusion and lateral movements were impossible, chewing was inadequate, a bilateral eyelash sign was present, and automatic-voluntary dissociation was also recognized. Reflexes were normal, except for an indifferent plantar response bilaterally. The patient did not require assistance for activities of daily living, such as eating, bathing, and dressing. She was described by one of her parents as stubborn, immature for her age, and prone to aggressive outbursts when frustrated; she showed a narrow range of interests and preferred to spend her time alone. During neuropsychologic evaluation, the patient appeared wakeful and sufficiently compliant, although easily

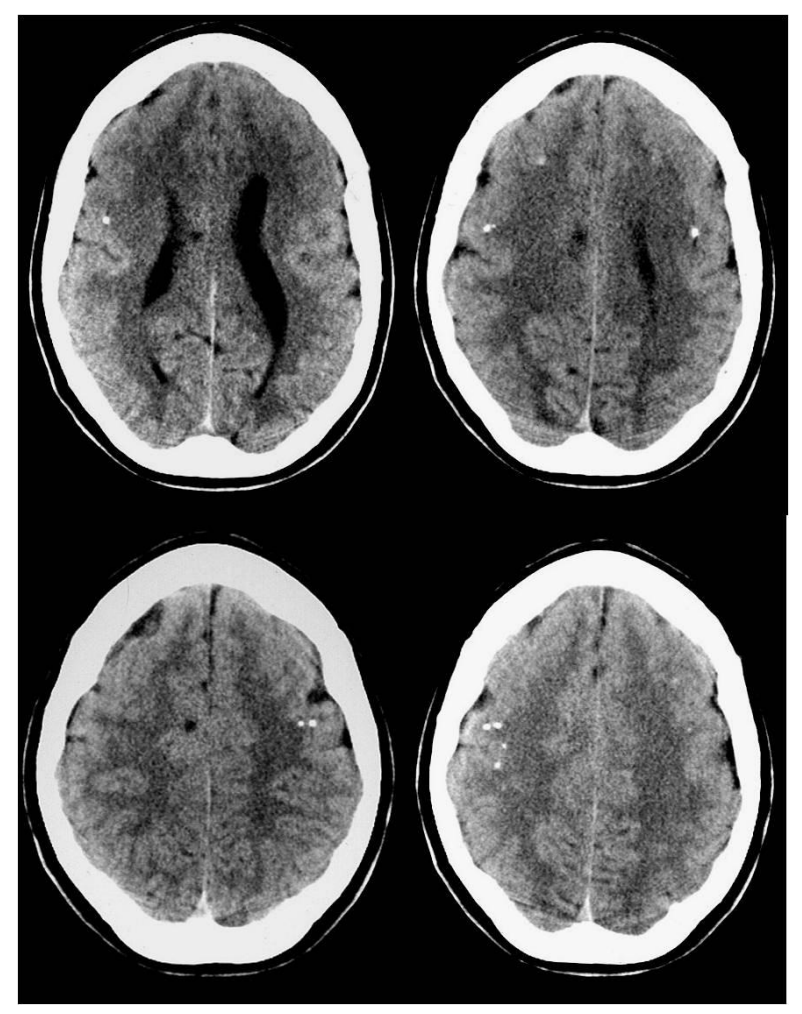

Figure I Axial computed tomography study of the brain. Notes: Minute cortical and subcortical calcifications located in bilateral frontal lobe. distracted and intolerant of errors. General cognitive abilities were found to be borderline impaired (intelligence quotient 77) when measured with Raven's Progressive Matrices. There was also evidence of impaired visuomotor coordination and severe deficits in attention and executive function.

A computed tomography brain study revealed a few bilateral cortical convolutions and microscopic subcortical calcifications (Figure 1), especially in the frontal regions. Magnetic resonance imaging (MRI) of the brain revealed smooth opercula and frontal (both superior and middle frontal circumvolutions) cortex (Figure 2A-D) and a "cobblestone" appearance in both frontal cortices (Figure 3). The Sylvian cisterns appeared vertical and shallow bilaterally. An electroencephalogram performed when she was 21 years old showed diffusely deregulated cerebral electrical activity together with ubiquitous fast paroxysms, prevalent in the left temporal area (Figure 4).

The patient has been undergoing logopedistic rehabilitation since one year of age; she also underwent psychomotor rehabilitation from 3 years up to 10 years of age, with an improvement in communicative ability and emotional control. Her salivary incontinence was ameliorated by administration of an anticholinergic drug (trihexyphenidyl $2 \mathrm{mg}$ twice daily).
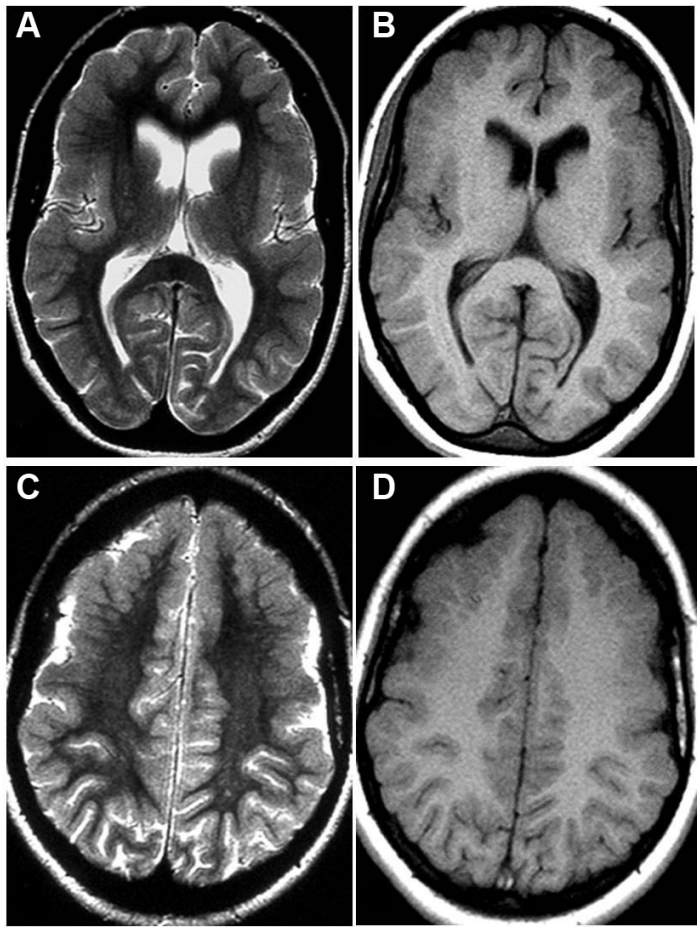

Figure 2 Axial Spin-Echo T2-weighted (A, C) and T1-weighted (B, D) magnetic resonance imaging study of the brain.

Notes: Developmental abnormalities (polymicrogyria) in the frontal opercular cortex bilaterally, more evident on the left side. 


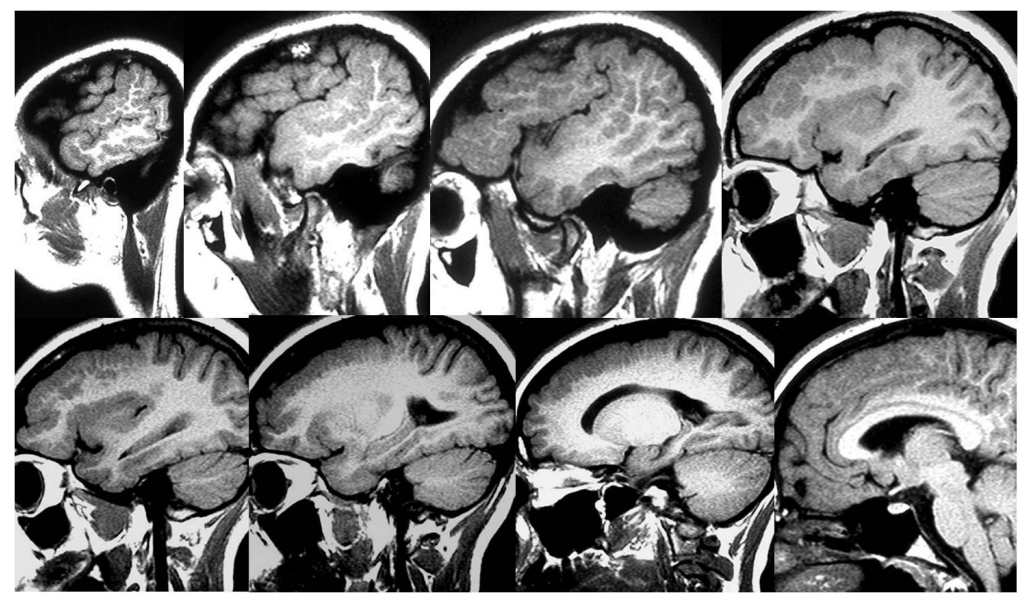

Figure 3 Spin-Echo T2-weighted sagittal projections on magnetic resonance imaging study of the brain. Notes: A "cobblestone" appearance is evident in the bilateral frontal opercular region.

\section{Discussion}

The main complications of congenital CMV infection in children are microcephaly, mental retardation, motor disabilities, neurosensorial deafness, ocular symptoms related to chorioretinitis, and epilepsy. Congenital CMV infections are clinically silent in the newborn period in $10 \%-15 \%$ of patients, and the extent of neurologic damage is highly variable. CMV can infect the developing germinative matrix of the brain and can cause lissencephaly if the infection occurs in the earlier half of the second trimester of pregnancy; if the infection occurs later, there is polymicrogyria. ${ }^{6}$ Therefore, the timing of the intrauterine infection is important

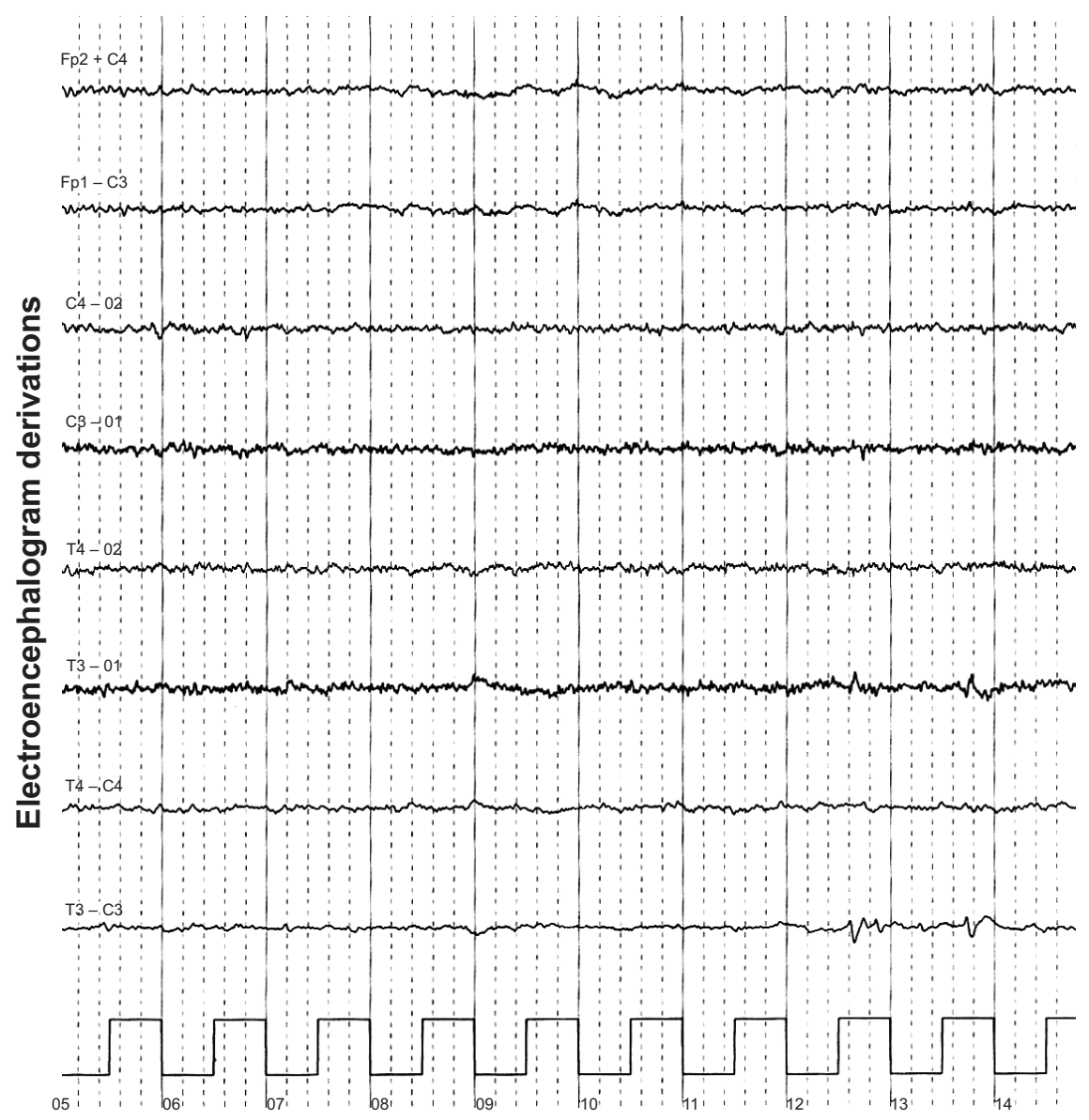

Time (s)

Figure 4 Electroencephalogram showing diffusely deregulated cerebral electrical activity together with ubiquitous fast paroxysms, prevalent in the left temporal area. 
in determining both the type and severity of the resulting developmental abnormality, and infections occurring in an earlier period of gestation can result in more severe malformations of cortical development than those occurring in later periods. ${ }^{7,8}$ Polymicrogyria would be due to infection in the first and second phase of the third trimester of gestation, and fetal ischemia can produce cerebral microgyria. ${ }^{9}$ It has been suggested that perfusion deficits can be caused by the CMV itself, which is able to infect endothelial cells of the intracranial vessels. ${ }^{10}$ One group of authors ${ }^{11}$ has described four cases of microgyria associated with intrauterine CMV infection; according to the literature, microgyria is a common neuropathologic feature of the disease, resulting not from a neurogenetic or a histogenetic disorder, but from a deficit of cerebral perfusion. The mechanisms of the brain damage caused by CMV infection are still unclear, but might include brain ischemia, vasculitis, or more probably, a transitory lowering or absence of systemic perfusion. ${ }^{11} \mathrm{MRI}$ is the gold standard for study of the brain in the event of neurologic complications of intrauterine CMV infection (neuronal migration abnormalities and cortical dysplasia). The main MRI findings are dilation of the ventricles and pericerebral spaces, oligo/ pachygyria, delayed myelination, and periventricular cysts. Intracranial calcifications are common (accounting for more than $77 \%$ of the abnormalities in patients with congenital CMV), although non-specific. ${ }^{7}$ The calcifications may be small and periventricular, sometimes thicker and straight, and are usually located at the corticosubcortical interface as well as near the basal ganglia. ${ }^{12,13}$ Calcifications are best seen on brain computed tomography.

The diagnostic problem of congenital CMV infection arises because of late diagnosis, usually after the neonatal period (that is, after 3 months of life). Nevertheless, its neurologic complications may become evident only around months 6-9 of life, when the diagnosis is no longer possible. In our case, the topography of the lesions and their bilateral distribution correlated with symptoms, since perisylvian lesions are typically associated with pseudobulbar palsy. Finally, the lesion in the frontal cortex correlates with mental retardation. $^{14}$

\section{Acknowledgment}

We thank Dr IM Conforti for the contribution offered to the clinical description by providing an extensive phoniatric evaluation of the patient.

\section{Disclosure}

The authors report no conflicts of interest in this work.

\section{References}

1. Domjan J, Millar J. The MRI appearances of anterior opercular syndrome in a child with recurrent herpes simplex encephalitis. Clin Radiol. 2000;55(7):574-575.

2. Ann MY, Liu OK, Wu YL. [Foix-Chavany-Marie syndrome]. Zhonghua Yi Xue Za Zhi. 2001;64(9):540-544. Chinese.

3. Christen HJ, Hanefeld F, Kruse E, Imhäuser S, Ernst JP, Finkenstaedt M. Foix-Chavany-Marie (anterior operculum) syndrome in childhood: a reappraisal of Worster-Drought syndrome. Dev Med Child Neurol. 2000;42(2):122-132.

4. Mateos V, Salas-Puig J, Campos DM, Carrero V, Andermann F. Acquired bilateral opercular lesions or Foix-Chavany-Marie syndrome and eating epilepsy. J Neurol Neurosurg Psychiatry. 1995;59(5):559-560.

5. Sasaguri H, Sodeyama N, Maejima Y, Kanda T, Mizusawa H. Slowly progressive Foix-Chavany-Marie syndrome associated with chronic herpes simplex encephalitis. J Neurol Neurosurg Psychiatry. 2002;73(2):203-204.

6. Joseph LD, Pushpalatha, Kuruvilla S. Cytomegalovirus infection with lissencephaly. Indian J Pathol Microbiol. 2008;51(3):402-404.

7. Zucca C, Binda S, Borgatti R, et al. Retrospective diagnosis of congenital cytomegalovirus infection and cortical maldevelopment. Neurology. 2003;61(5):710-712.

8. Golden JA. Cell migration and cerebral cortical development. Neuropathol Appl Neurobiol. 2001;27(1):22-28.

9. Barkovich AJ, Rowley H, Bollen A. Correlation of prenatal events with the development of polymicrogyria. Am J Neuroradiol. 1995; 16(4 Suppl):822-827.

10. van Den Pol AN, Mocarski E, Saederup N, Vieira J, Meier TJ. Cytomegalovirus cell tropism, replication, and gene transfer in brain. J Neurosci. 1999;19(24):10948-10965.

11. Marques Dias MJ, Harmant-van Rijckevorsel G, Landrieu P, Lyon G. Prenatal cytomegalovirus disease and cerebral microgyria: evidence for perfusion failure, not disturbance of histogenesis, as the major cause of fetal cytomegalovirus encephalopathy. Neuropediatrics. 1984;15(1):18-24.

12. Boesch C, Issakainen J, Kewitz G, Kikinis R, Martin E, Boltshauser E. Magnetic resonance imaging of the brain in congenital cytomegalovirus infection. Pediatr Radiol. 1989;19(2):91-93.

13. Alonso A, Alvarez A, Seara MJ, Liñares M, Villalón J. Unusual manifestations of postnatally acquired cytomegalovirus infection: findings on CT and MR. Pediatr Radiol. 1996;26(11):772-774.

14. Balaji R, Mangaleswaran B, John R. Frontoethmoidal encephalocele with subependymal nodular heterotopia: an unusual association. A case report. Neuroradiol J. 2010;23(3):317-320.
Neuropsychiatric Disease and Treatment

\section{Publish your work in this journal}

Neuropsychiatric Disease and Treatment is an international, peerreviewed journal of clinical therapeutics and pharmacology focusing on concise rapid reporting of clinical or pre-clinical studies on a range of neuropsychiatric and neurological disorders. This journal is indexed on PubMed Central, the 'PsycINFO' database and CAS,
Submit your manuscript here: http://www.dovepress.com/neuropsychiatric-disease-and-treatment-journal

and is the official journal of The International Neuropsychiatric Association (INA). The manuscript management system is completely online and includes a very quick and fair peer-review system, which is all easy to use. Visit http://www.dovepress.com/testimonials.php to read real quotes from published authors. 